\title{
Atención y tratamiento integral de la dermatitis atópica
}

\section{Clinical approach and therapeutic management of atopic dermatitis}

Marian Rivas-Calderón, Luz Orozco-Covarrubias, Marimar Sáez-de-Ocariz

\section{ANTECEDENTES}

La dermatitis atópica es la enfermedad cutánea inflamatoria más común, afecta principalmente a los niños (prevalencia de 20\%) y suele iniciarse antes de los 5 años (90\%). ${ }^{1}$ El curso clínico es crónico y genera recidiva; dos tercios de los pacientes se controlan en la etapa adulta. ${ }^{2}$ La fisiopatología resulta de la interacción de factores genéticos, inmunológicos y ambientales, con disfunción de la barrera cutánea y desequilibrio inmunitario, además de elevada pérdida transepidérmica de agua, inflamación y mayor permeabilidad a los alergenos, irritantes y microorganismos. ${ }^{3}$

Los signos cardinales incluyen: xerosis y prurito. En el lactante (2-24 meses) se observan lesiones eritemato-escamosas exudativas en las mejillas y superficies extensoras de las extremidades, sin afectar el área del pañal (Figura 1a-b). En preescolares-escolares (2-12 años) las lesiones son menos exudativas y más liquenificadas, con distribución flexural (Figura 2a-b). En los adolescentes (mayores de 12 años) las lesiones son más localizadas y liquenificadas. Algunas variantes con morfología atípica se muestran en el Cuadro 1, Figura 3a-e.,

El diagnóstico se establece con la topografía, morfología, síntomas y evolución de la dermatosis. Los criterios diagnósticos más utilizados, con fines de investigación, ${ }^{2}$ son los de Hanifin y Rajka $(1980)^{5}$ y los del Grupo Británico (1994). ${ }^{6}$

La dermatitis atópica puede complicarse con infecciones. Las infecciones bacterianas, sobre todo por $S$ aureus, provocan impétigo y foliculitis, y
Servicio de Dermatología, Instituto Nacional de Pediatría, Ciudad de México.

Recibido: 6 de agosto 2020

Aceptado: 30 de octubre 2020

Correspondencia Marimar Sáez de Ocariz mmsaezdeocariz@gmail.com Este artículo debe citarse como Rivas-Calderón M, Orozco-Covarrubias L, Sáez-de-Ocariz M. Atención y tratamiento integral de la dermatitis atópica. Acta Pediatr Mex 2020; 41(6): 286-92 
Rivas-Calderón M, et al. Atención y tratamiento de la dermatitis atópica
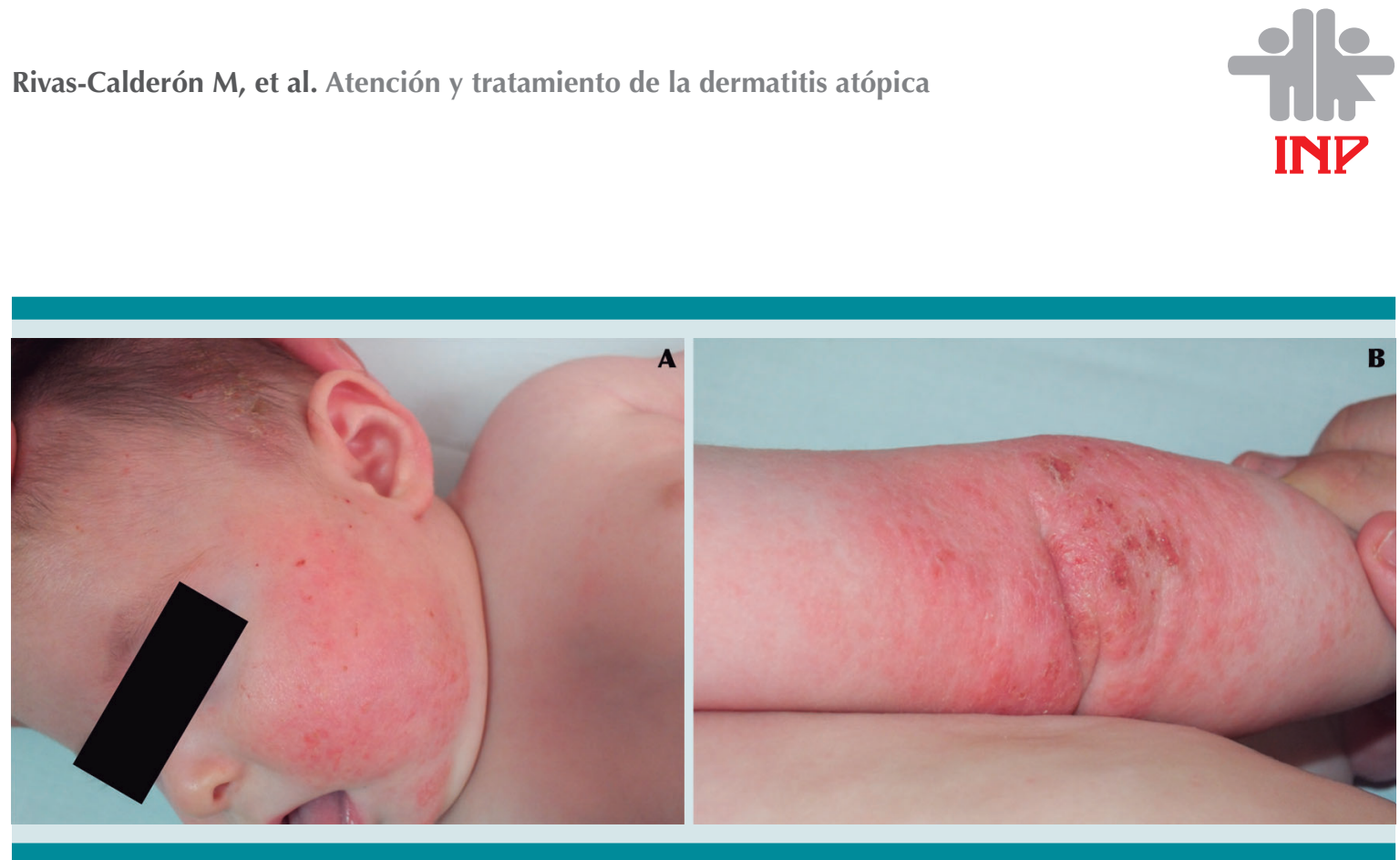

Figura 1. Dermatitis atópica del lactante. A) Placas eritematoescamosas en las mejillas, sin afectación del área centrofacial; B) placas eritematoescamosas, exudativas en el área extensora del brazo.

Cuadro 1. Variantes morfológicas de dermatitis atópica

\begin{tabular}{|c|c|}
\hline Variante & Características \\
\hline Folicular & $\begin{array}{l}\text { Pacientes pediátricos de cualquier edad. } \\
\text { Ambos géneros. } \\
\text { Manifestación frecuente en invierno. } \\
\text { Más común en afroamericanos, hispanos } \\
\text { o asiáticos. } \\
\text { Acentuación folicular importante. } \\
\text { Prurito severo. }\end{array}$ \\
\hline $\begin{array}{l}\text { Papular } \\
\text { liquenoide }\end{array}$ & $\begin{array}{l}\text { Lactantes. } \\
\text { Ambos géneros. } \\
\text { Manifestación frecuente en verano. } \\
\text { Más común en afroamericanos e hispanos. } \\
\text { Pápulas eritematosas, aplanadas. } \\
\text { Superficies extensoras de las extremidades } \\
\text { superiores e inferiores (dorso de las manos, } \\
\text { codos, rodillas). } \\
\text { Prurito importante. }\end{array}$ \\
\hline Prúrigo & $\begin{array}{l}\text { Prescolares y escolares. } \\
\text { Ambos géneros. } \\
\text { Múltiples nódulos eritemato-violáceos, } \\
\text { hiperqueratósicos y excoriados. } \\
\text { Prurito crónico y recalcitrante. }\end{array}$ \\
\hline Numular & $\begin{array}{l}\text { Preescolares y escolares. } \\
\text { Afección frecuente en hombres. } \\
\text { Placas numulares (del lat. nummus, mone- } \\
\text { da.), eritematoescamosas, exudativas y con } \\
\text { excoriaciones. } \\
\text { Superficies extensoras de las extremidades, } \\
\text { muñecas, tobillos. }\end{array}$ \\
\hline Eritrodérmica & $\begin{array}{l}\text { Prescolares y escolares. } \\
\text { Ambos géneros. } \\
\text { Eritema en } 90 \% \text { de la superficie corporal }\end{array}$ \\
\hline
\end{tabular}

empeoran el eccema. El eccema herpeticum es una complicación causada por el virus del herpes simple (VHS); genera múltiples vesículas umbilicadas, erosiones en sacabocado (Figura 4a-b), fiebre y malestar general. Otra infección frecuente es el molusco contagioso. ${ }^{7}$ Los principales diagnósticos diferenciales se muestran en el Cuadro 2. El objetivo del tratamiento se dirige a controlar la enfermedad a largo plazo, prevenir las complicaciones y mejorar la calidad de vida de los pacientes. ${ }^{8-11}$

\section{Medidas generales}

El éxito del tratamiento se fundamenta en los cuidados de la piel y aplicación de soluciones hidratantes de forma frecuente. ${ }^{9}$ Se recomienda el baño diario con agua tibia, sustitutos de jabón y evitar frotar la piel; el secado debe ser delicado seguido por la aplicación del hidratante. ${ }^{9}$ En pacientes con dermatitis atópica moderada-grave se recomiendan baños con cloro, a concentración de $0.005-0.009 \%$ ( $1 \mathrm{~mL}$ de cloro al $6.34 \%$ por cada litro de agua), durante 10 minutos, 2 veces por semana. ${ }^{9}$ Es importante usar ropa de algodón, lavada con detergente líquido, sin suavizantes ni blanqueadores. ${ }^{12}$ Las pijamas 


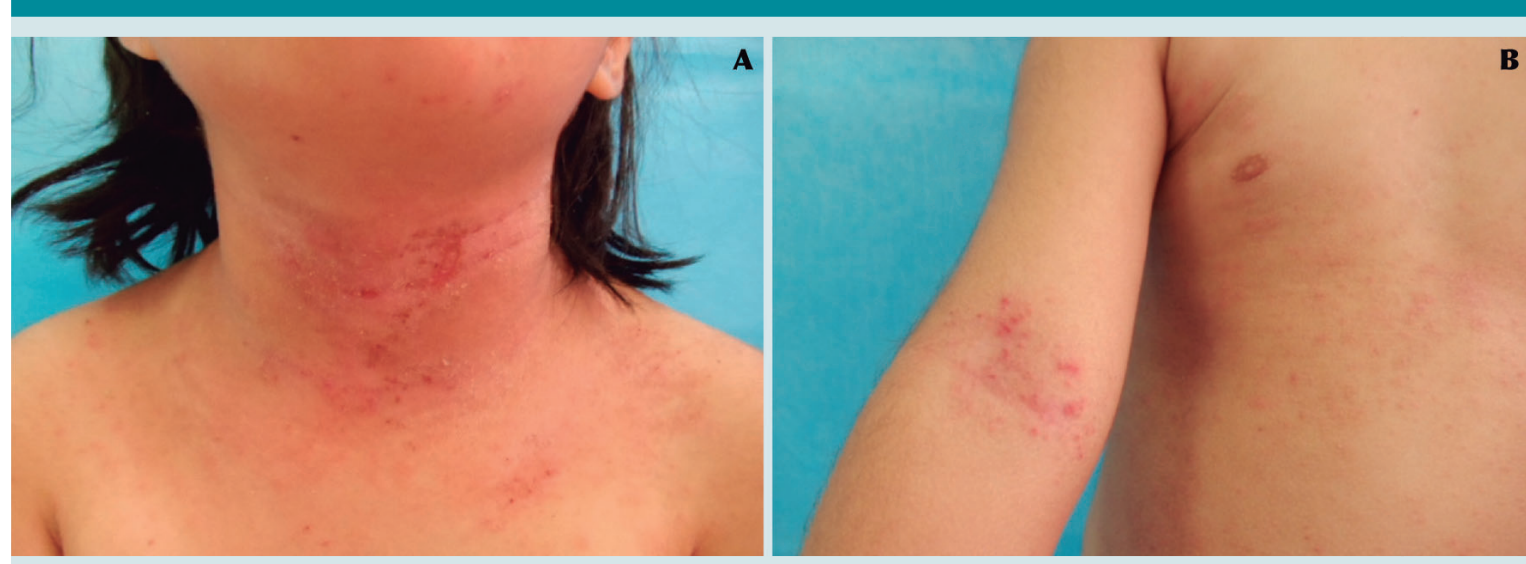

Figura 2. Dermatitis atópica del preescolar-escolar, con afectación flexural. Placas eritematoescamosas, liquenificadas y excoriadas en la cara anterior del cuello A) y la fosa antecubital derecha B).
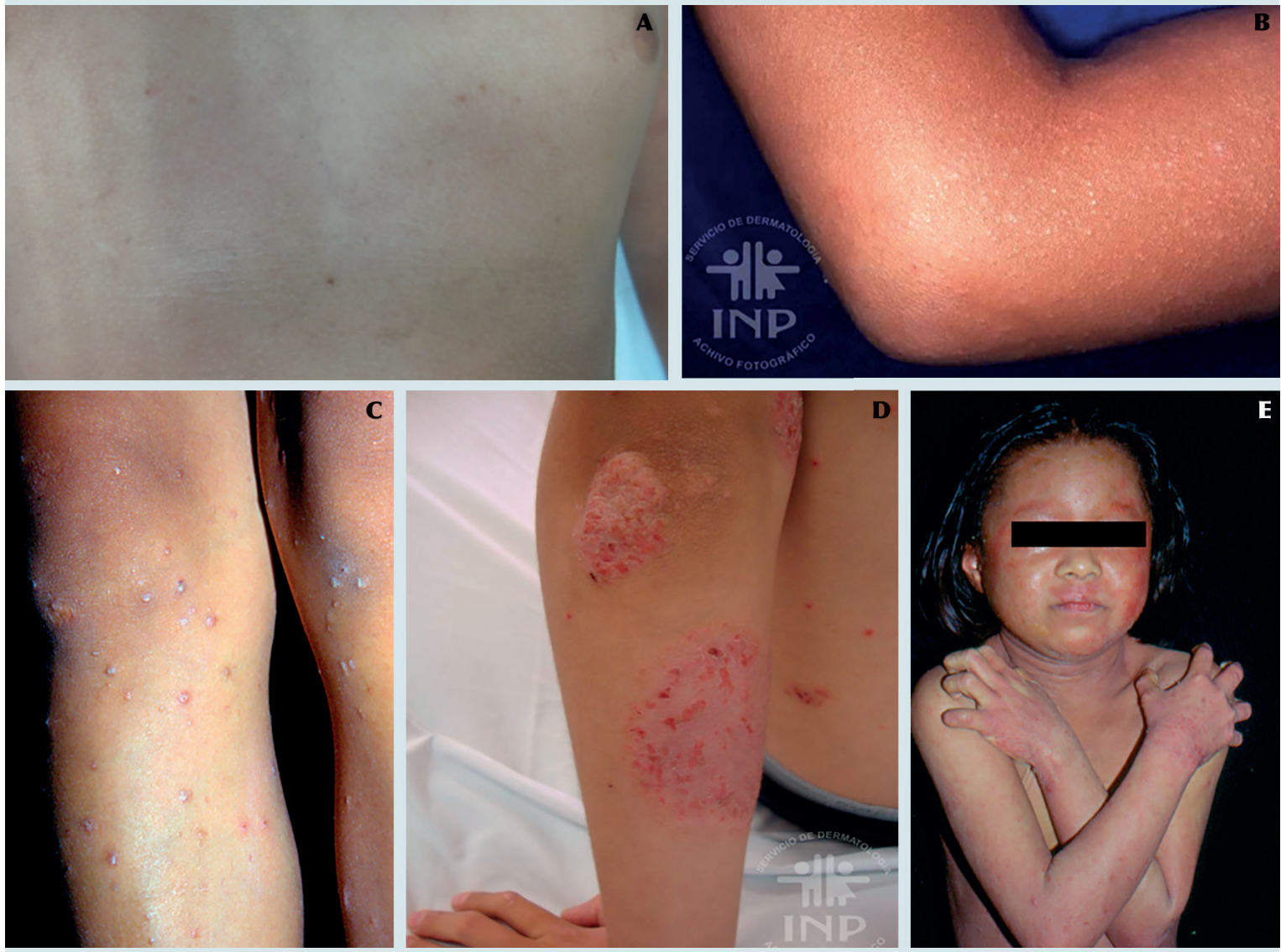

Figura 3. Variantes morfológicas de la dermatitis atópica: A) folicular; B) papular liquenoide; C) tipo prúrigo; D) tipo eccema numular; E) eritrodérmica. 
Rivas-Calderón $\mathrm{M}$, et al. Atención y tratamiento de la dermatitis atópica

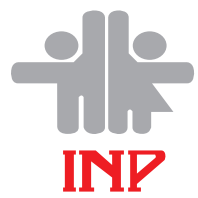

húmedas reducen rápidamente la severidad del brote al disminuir la pérdida de agua, aumentar la penetración del esteroide tópico y funcionan como barrera contra el rascado. Cuadro $3^{9}$

\section{Medidas farmacológicas}

\section{Antiinflamatorios tópicos}

Los esteroides tópicos representan el tratamiento de primera línea para el control de los brotes. La elección de la potencia desde muy baja hasta superpotente- depende de diversos factores, sobre todo el sitio de aplicación (se indican potencias bajas en la cara, los pliegues y genitales) y periodo de tratamiento (pueden indicarse potencias bajas por periodos más prolongados y altas durante dos semanas, como límite máximo). Se aplican dos veces al día hasta controlar el brote, con disminución paulatina y suspensión del fármaco. ${ }^{9}$ También pueden prescribirse como terapia de mantenimiento (dos días a la semana) porque reducen el riesgo de brotes y prolongan el tiempo de recidiva. ${ }^{11}$ Los efectos adversos locales (atrofia,

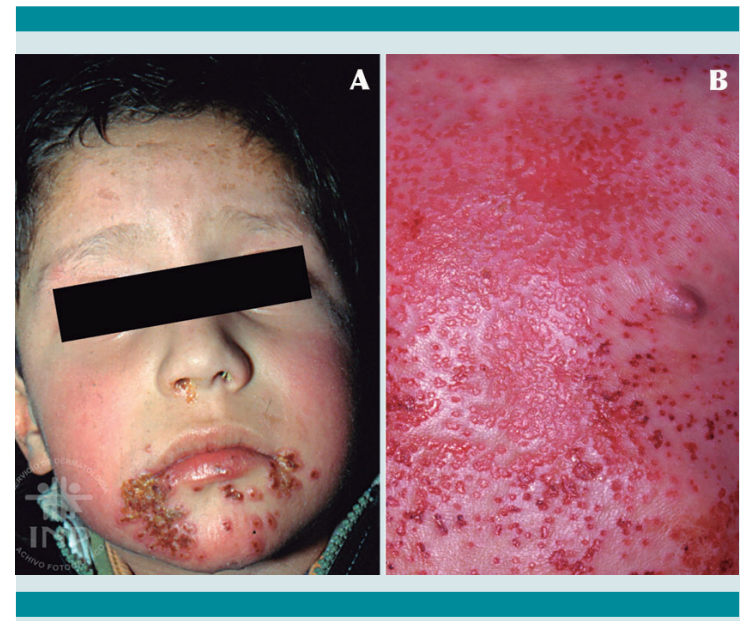

Figura 4. Eccema herpeticum. A) Localizado en la región perioral con formación de vesículas, costras melicéricas, costras sanguíneas y exulceraciones en sacabocado; B) diseminación con afectación grave del tronco y numerosas exulceraciones en sacabocado que coalescen al formar placas. hipertricosis, dermatitis acneiforme) son frecuentes en quienes reciben altas, principalmente en quienes tienen piel delgada, áreas extensas de dermatitis o cuyo régimen es prolongado. ${ }^{9}$

Los inhibidores de la calcineurina (tacrolimus y pimecrolimus) son efectivos en la cara, los pliegues y genitales, cuando existen efectos adversos relacionados con los esteroides tópicos o se requiere tratamiento durante mucho tiempo. Se indican dos veces al día en pacientes con brotes y dos veces por semana en terapia de mantenimiento. ${ }^{8-9,11,12}$

\section{Antimicrobianos}

En pacientes con infecciones bacterianas es importante elegir los antibióticos tópicos con bajo grado de sensibilización (mupirocina o ácido fusídico). Los antibióticos sistémicos se indican a pacientes con evidencia clínica de infección bacteriana y no de manera rutinaria. Aciclovir debe indicarse en el tratamiento del eccema herpeticum por vía oral $(20 \mathrm{mg} / \mathrm{kg} / 6 \mathrm{~h}$ por $5-7$ días) o intravenosa (5 mg/kg/8 h).8,11,13

Debido al riesgo de efectos adversos no se recomienda el uso de preparados combinados con antibióticos tópicos, antimicóticos y esteroides tópicos de alta potencia.

\section{Antihistamínicos}

Si bien no existe evidencia para recomendarlos en el tratamiento de la dermatitis atópica, los antihistamínicos sedantes pueden beneficiar al paciente con alteraciones del sueño secundarias al prurito., ${ }^{8,10}$

\section{Fototerapia}

Es el tratamiento de segunda línea para pacientes con dermatitis atópica moderada-grave. La foto- 
Cuadro 2. Diagnóstico diferencial de la dermatitis atópica (continua en la siguiente página)

\begin{tabular}{|c|c|c|c|}
\hline Causas & Enfermedad & Morfología y distribución & Otros \\
\hline \multirow[t]{2}{*}{ Infecciones } & Escabiasis & $\begin{array}{l}\text { Pápulas eritematosas, pústulas, vesículas, } \\
\text { surcos y excoriaciones. } \\
\text { Muñecas, espacios interdigitales, palmas, } \\
\text { plantas, axilas, ombligo, área del pañal. }\end{array}$ & $\begin{array}{l}\text { Prurito de predominio noc- } \\
\text { turno. } \\
\text { Otros familiares afectados. }\end{array}$ \\
\hline & Tiñas & $\begin{array}{l}\text { Placas eritematoescamosas anulares o } \\
\text { policíclicas, borde elevado, crecimiento } \\
\text { centrífugo. } \\
\text { Cualquier parte del cuerpo, asimétricas. }\end{array}$ & $\begin{array}{l}\text { Los esteroides tópicos } \\
\text { enmascaran el cuadro. } \\
\text { Contacto con mascotas. }\end{array}$ \\
\hline \multirow[t]{2}{*}{ Inflamatorias } & $\begin{array}{l}\text { Dermatitis seborreica de la } \\
\text { infancia }\end{array}$ & $\begin{array}{l}\text { Placas eritematosas con escama oleosa } \\
\text { amarillenta. } \\
\text { Piel cabelluda, cejas, canal auditivo exter- } \\
\text { no, área del pañal, axilas, ombligo. }\end{array}$ & $\begin{array}{l}\text { Enfermedad asintomática o } \\
\text { prurito leve. }\end{array}$ \\
\hline & Psoriasis & $\begin{array}{l}\text { Placas eritematosas con escama gruesa } \\
\text { blanquecina, bien delimitadas, signo de } \\
\text { Auspitz. } \\
\text { Piel cabelluda, ombligo, área del pañal, } \\
\text { otros pliegues. }\end{array}$ & $\begin{array}{l}\text { Antecedentes familiares de } \\
\text { psoriasis. }\end{array}$ \\
\hline Neoplásicas & $\begin{array}{l}\text { Micosis fungoides } \\
\text { hipopigmentada }\end{array}$ & $\begin{array}{l}\text { Manchas hipopigmentadas, algunas veces } \\
\text { con escama fina. } \\
\text { Predominante en la espalda, el abdomen, } \\
\text { los glúteos y muslos. }\end{array}$ & $\begin{array}{l}\text { Recalcitrante a cuidados de la } \\
\text { piel y esteroides tópicos. }\end{array}$ \\
\hline \multirow[t]{5}{*}{ Otras } & Pitiriasis alba & $\begin{array}{l}\text { Manchas hipopigmentadas circulares, mal } \\
\text { definidas, diversos tamaños, con escama } \\
\text { fina. } \\
\text { Áreas expuestas al sol (cara). }\end{array}$ & $\begin{array}{l}\text { Asintomáticas. } \\
\text { Disminuye con fotoprotección } \\
\text { y cuidados de la piel. }\end{array}$ \\
\hline & Ictiosis vulgar & $\begin{array}{l}\text { Xerosis, hiperlinearidad palmoplantar, } \\
\text { escama poligonal gruesa, fisuras. } \\
\text { Zonas flexurales respetadas. }\end{array}$ & $\begin{array}{l}\text { Pueden tener familiares afec- } \\
\text { tados. }\end{array}$ \\
\hline & $\begin{array}{l}\text { Inmunodeficiencias } \\
\text { - Síndrome de Wiskott- } \\
\text { Aldrich } \\
\text { - Síndrome hiper-IgE } \\
\text { - Inmunodeficiencias com- } \\
\text { binadas graves (síndrome } \\
\text { de OMENN e IPEX) }\end{array}$ & $\begin{array}{l}\text { Placas eritematoescamosas que evolucio- } \\
\text { nan a eritrodermia en los primeros meses } \\
\text { de vida. } \\
\text { Otros: petequias, púrpura, infecciones } \\
\text { cutáneas. }\end{array}$ & $\begin{array}{l}\text { Asociada con infecciones de } \\
\text { repetición. } \\
\text { Otros síntomas: diarrea, fallo } \\
\text { de medro, retraso psicomotor, } \\
\text { entre otros. } \\
\text { Alteraciones en los exámenes } \\
\text { de laboratorio, específicas de } \\
\text { cada padecimiento. }\end{array}$ \\
\hline & Acrodermatitis enteropática & $\begin{array}{l}\text { Placas eritematoescamosas. } \\
\text { Periorificiales y acrales (manos, pies, } \\
\text { glúteos). }\end{array}$ & $\begin{array}{l}\text { Alopecia, diarrea, curación } \\
\text { deficiente de las heridas. }\end{array}$ \\
\hline & & & $\begin{array}{l}\text { Mejoría con suplemento de } \\
\text { zinc. }\end{array}$ \\
\hline
\end{tabular}

terapia UVB de banda estrecha, es la modalidad más estudiada en pacientes pediátricos, con respuesta satisfactoria en $40-90 \%$ de los casos, mejoría de los índices de calidad de vida y periodos prolongados sin recidiva. ${ }^{14}$

\section{Inmunomoduladores sistémicos}

Se indican en caso de falla al régimen con emolientes, antiinflamatorios o fototerapia. ${ }^{10}$ Los más efectivos son: ciclosporina, metotrexato, micofeno- 
Rivas-Calderón $\mathrm{M}$, et al. Atención y tratamiento de la dermatitis atópica

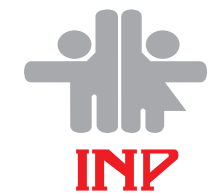

Cuadro 3. Técnica de aplicación de pijamas húmedas.

1. La pijama húmeda debe usarse después del baño.

2. El esteroide tópico se aplica en las lesiones inflamatorias, sobre todo de potencia baja-moderada, pues se incrementa su absorción. Posteriormente debe aplicarse el emoliente en todo el cuerpo.

3. Se coloca la pijama de algodón húmeda (muy bien exprimida).

4. Sobre la pijama húmeda se coloca otra pijama de algodón seca.

5. Puede utilizarse durante 8 a 24 horas por día (generalmente se usa por la noche), todos los días durante dos semanas.

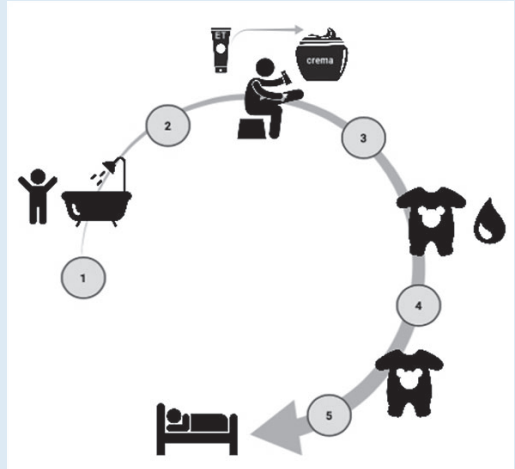

lato de mofetilo y azatioprina. ${ }^{10}$ Deben prescribirse por un especialista, e individualizar el tratamiento según las opciones disponibles, análisis del riesgobeneficio y preferencia del paciente. ${ }^{15}$

No se recomiendan los esteroides sistémicos, excepto como "puente" mientras otros tratamientos inician su efecto pues, aunque suprimen temporalmente la enfermedad, existe el riesgo de brotes graves al suspenderlos y pueden generar efectos adversos. ${ }^{9,11,16}$

\section{Biológicos}

Dupilumab es el único fármaco aprobado para el tratamiento de niños y adolescentes con dermatitis atópica. Es un anticuerpo monoclonal contra el receptor de IL-4. ${ }^{17}$ En México está aprobado solo en adultos y próximamente en adolescentes.

\section{Prevención}

Diversos estudios sugieren que el tratamiento profiláctico con emolientes durante el periodo neonatal reduce el riesgo de dermatitis atópica, incluso en $50 \%$ de los niños con predisposición. ${ }^{18}$ Sin embargo, recientemente se publicaron ensayos clínicos que discuten su efectividad. ${ }^{19,20} \mathrm{La}$ administración de probióticos pre y posnatales ha demostrado disminuir el riesgo de dermatitis atópica. ${ }^{18}$ Evitar el consumo de alimentos alergénicos durante el embarazo, la lactancia o a edades tempranas no representa una estrategia comprobada para prevenir la dermatitis atópica.

\section{Educación terapéutica}

Los programas educativos son importantes para adiestrar al paciente a controlar su enfermedad. Se ha demostrado que la combinación de esta estrategia y la terapia convencional disminuyen la gravedad de la dermatitis atópica. ${ }^{21-23}$

\section{REFERENCIAS}

1. Silverberg JI. Public health burden and epidemiology of atopic dermatitis. Dermatol Clin 2017; 35 (3): 283-9. doi. 10.1016/j.det.2017.02.002.

2. Eichenfield $L F$, et al. Guidelines of care for the management of atopic dermatitis: Section 1. Diagnosis and assessment of atopic dermatitis. J Am Acad Dermatol 2014; 70 (2): 338-51. doi. 10.1016/j.jaad.2013.10.010

3. Weidinger $S$, et al. Atopic dermatitis. Lancet $2016 ; 387$ (10023): 1109-22. doi: 10.1016/S0140-6736(15)00149-X.

4. Julián-Gónzalez RE, et al. Less common clinical manifestations of atopic dermatitis: Prevalence by age. Pediatr Dermatol 2012; 29 (5): 580-583. doi. 10.1111/j.15251470.2012.01739.x.

5. Hanifin JM, et al. Diagnostic features of atopic dermatitis. Acta Derm Venereol 1980; 92 (Suppl 1): 44-47. 
https://www.medicaljournals.se/acta/content_files/files/ pdf/60/92/924447.pdf

6. Williams HC, et al. The UK working party's diagnostic criteria for atopic dermatitis. I. Derivation of a minimum set of discriminators for atopic dermatitis. $\mathrm{Br} J$ Dermatol 1994; 131 (3): 383-396. doi. 10.1111/j.1365-2133.1994. tb08530.x.

7. Yarbrough $\mathrm{KB}$, et al. Atopic dermatitis: Complications. En: Hoeger P, Kinsler V, Yan A. Harper's Textbook of Pediatric Dermatology. $4^{\text {a }}$ ed. New Jersey: Wiley-Blackwell, 2020; 245-52.

8. Souto EB, et al. Trends in atopic dermatitis -From standard pharmacotherapy to novel drug delivery systems. Int J Mol Sci 2019; 20 (22): 5659. doi. 10.3390/ijms20225659

9. Eichenfield $L F$, et al. Guidelines of care for the management of atopic dermatitis: Section 2. Management and treatment of atopic dermatitis with topical therapies. J Am Acad Dermatol 2014; 71 (1): 116-32. doi. 10.1016/j. jaad.2014.03.023.

10. Sidbury R, et al. Guidelines of care for the management of atopic dermatitis: Section 3. Management and treatment with phototherapy and systemic agents. J Am Acad Dermatol 2014; 71 (2): 327-49. doi. 10.1016/j.jaad.2014.03.030.

11. Sidbury R, et al. Guidelines of care for the management of atopic dermatitis: Section 4. Prevention of disease flares and use of adjunctive therapies and approaches. J Am Acad Dermatol 2014; 71 (6): 1218-33. doi. 10.1016/j. jaad.2014.08.038.

12. Rincón-Pérez $C$, et al. Consenso mexicano para el diagnóstico y tratamiento de la dermatitis atópica en adolescentes y adultos. Rev Alerg Mex 2018; 65 (Supl 2): s8-s88. doi. 10.29262/ram.v65i6.526

13. American Academy of Pediatrics. Herpes Simplex. En: Kimberlin DW, Brady MT, Jackson MA, Long SS. Red Book: 2018 Report of the Committee on Infectious Diseases. American Academy of Pediatrics, 2018; 437-49.
14. Juarez $\mathrm{MC}$, et al. Phototherapy in the pediatric population. Dermatol Clin 2020; 38 (1): 91-108. doi. 10.1016/j. det.2019.08.012

15. Sidbury R, et al. Atopic dermatitis guidelines: Diagnosis, systemic therapy, and adjunctive care. Clin Dermatol 2018; 36 (5): 648-52. doi. 10.1016/j.clindermatol.2018.05.008

16. Drucker AM, et al. Use of systemic corticosteroids for atopic dermatitis: International Eczema Council Consensus Statement. Br J Dermatol 2018; 178 (3): 768-75. doi. 10.1111/bjd.15928.

17. von Hove $\mathrm{M}$, et al. Biologicals in the treatment of pediatric atopic diseases. Handb Exp Pharmacol 2020; 261: 131-151. doi. 10.1007/164_2019_307

18. Boulos S, et al. Current concepts in the prevention of atopic dermatitis. Clin Dermatol 2018; 36 (5): 668-71. doi. 10.1016/j.clindermatol.2017.03.004

19. Chalmers JR, et al. Daily emollient during infancy for prevention of eczema: the BEEP randomised controlled trial. Lancet 2020; 395 (10228): 962-72. doi. 10.1016/ S0140-6736(19)32984-8

20. Skjerven HO, et al. Skin emollient and early complementary feeding to prevent infant atopic dermatitis (PreventADALL): A factorial, multicentre, cluster-randomised trial. Lancet 2020; 395 (10228): 951-61. doi. 10.1016/ S0140-6736(19)32983-6.

21. Liang $\mathrm{Y}$, et al. Therapeutic patient education in children with moderate to severe atopic dermatitis: A multicenter randomized controlled trial in China. Pediatr Dermatol 2018; 35 (1): 70-5. doi. 10.1111/pde.13362

22. Grossman SK, et al. Experiences with the first eczema school in the United States. Clin Dermatol 2018; 36 (5): 662-7. doi. 10.1016/j.clindermatol.2018.05.006.

23. Lee $Y$, et al. Educational programs for the management of childhood atopic dermatitis: An integrative review. Asian Nursing Res 2015; 9 (3): 185-93. doi. 10.1016/j. anr.2015.06.002 